\title{
Decadal climate variability in the Argentine Pampas: regional impacts of plausible climate scenarios on agricultural systems
}

\author{
Guillermo Podestá ${ }^{1, *}$, Federico Bert ${ }^{2}$, Balaji Rajagopalan ${ }^{3}$, Somkiat Apipattanavis ${ }^{3}$, \\ Carlos Laciana ${ }^{4}$, Elke Weber ${ }^{5}$, William Easterling ${ }^{6}$, Richard Katz ${ }^{7}$, David Letson ${ }^{1}$, \\ Angel Menendez ${ }^{2}$

\footnotetext{
${ }^{1}$ Rosenstiel School of Marine and Atmospheric Science, University of Miami, 4600 Rickenbacker Causeway, Miami, Florida 33149, USA

${ }^{2}$ Universidad de Buenos Aires, Av. San Martín 4453, Buenos Aires, Argentina

${ }^{3}$ Department of Civil, Environmental, and Architectural Engineering, University of Colorado, Campus Box 428, ECOT 541, Boulder, Colorado 80309, USA

${ }^{4}$ Department of Psychology and Business School, Columbia University, Uris Hall 716, 3022 Broadway, New York, New York 10027-6902, USA

${ }^{5}$ College of Earth and Mineral Sciences, The Pennsylvania State University, 116 Deike Building, University Park, Pennsylvania 16802, USA
} \\ ${ }^{6}$ Institute for the Study of Society and Environment, National Center for Atmospheric Research, PO Box 3000, Boulder, \\ Colorado 80307, USA
}

\begin{abstract}
The Pampas of Argentina have shown some of the most consistently increasing trends in precipitation during the 20th century. The rainfall increase has partly contributed to a significant expansion of agricultural area, particularly in climatically marginal regions of the Pampas. However, it is unclear if current agricultural production systems, which evolved partly in response to enhanced climate conditions, may remain viable if (as entirely possible) climate reverts to a drier epoch. We assess the potential impacts of a plausible decreasing trend in precipitation on the economic sustainability of 2 contrasting agricultural systems in the Pampas: Pergamino, in the most productive subregion of the Pampas, and Pilar, in the northern, semi-arid margin of the region. Also, we explore the scope for adaptation to changing climate. In the case where there is no adaptation, if precipitation decreases, as is plausible, impacts may be quite different between locations: whereas in Pergamino crop economic returns would not change noticeably, the more marginal Pilar would experience a marked decrease in profits and an increase in production risks. However, potential negative impacts might be mitigated, in part, if farmers adapt their agronomic management using current available technology or know-how.
\end{abstract}

KEY WORDS: Climate impacts · Climate scenarios - Adaptation - Decision-making $\cdot$ Cumulative prospect theory $\cdot$ Crop models $\cdot$ Argentina $\cdot$ Land allocation $\cdot$ Genetic algorithms

\section{INTRODUCTION}

As agricultural production is one of the sectors of society most vulnerable to climate variability and change (Parry \& Carter 1989, Meinke et al. 2006), it is important to explore linkages between complex agri- cultural ecosystems, uncertain trajectories of future climate, and land use changes over periods of a few decades, a scale relevant to sustainable resource management.

Our focus is on crop production systems in the region of central eastern Argentina known as the Pampas, 
one of the most important cereal- and oilseed-producing regions in the world (Hall et al. 1992). This region has shown some of the most significant trends in precipitation during the 20th century (Giorgi 2002). A steady increase in both annual and extreme precipitation has been observed in the Pampas since the 1960s (Rusticucci \& Penalba 2000, Minetti et al. 2003, Boulanger et al. 2005). Rainfall changes have been distributed unevenly through the seasonal cycle: increases concentrated in late spring to summer, whereas winter has seen little or no change. Furthermore, the increase has been particularly marked near the western margin of the Pampas, displacing westward the transition to semi-arid regions that represent the boundary of rainfed agriculture (Berbery et al. 2006). Different patterns of decadal variability have been proposed for Argentina, ranging from 'regime shifts' to linear increases in rainfall (Minetti \& Vargas 1997, Minetti et al. 2003). Rainfall changes in the Pampas are consistent with patterns observed elsewhere in South America. Haylock et al. (2006) showed a change to wetter conditions in Ecuador and northern Peru, as well as in southern Brazil, Paraguay and Uruguay.

The rainfall increase has partly contributed to major changes in land use patterns in the Pampas (Viglizzo et al. 1995, 1997, Magrín et al. 2005, Paruelo et al. 2005, Satorre 2005). The dynamic interaction of climate variability and economic, social, and technological drivers has resulted in a significant expansion of the area dedicated to agriculture, particularly in marginal regions of the Pampas (Schnepf et al. 2001, Paruelo et al. 2005). In places where agriculture was previously established, continuous cropping has widely replaced grain-pasture rotations. One remarkable process has been the impressive expansion of soybeans in the Pampas and the rest of Argentina: introduced in the early 1970s, soybean area (production) reached 5.1 Mha (11 Mt) in 1990 and exploded to 15.0 Mha (40+ Mt) in 2006, displacing other crops, pastures, and forests.

Recent awareness of the impacts of precipitation fluctuations on land use and production systems in the Pampas has heightened stakeholders' concerns about a possible return to drier conditions. It is unclear whether current agricultural production systems, which evolved partly in response to enhanced climate conditions, will be viable if (as entirely possible) climate reverts to a drier epoch. Some reports already suggest a return to lower rainfall in the Pampas (Minetti et al. 2003). Unfortunately, much uncertainty remains regarding the projected paths of future climate, particularly on regional scales and short time horizons (25 to 30 yr hence) (Boulanger et al. 2007). Despite the uncertainty, the agricultural sector is increasingly demanding actionable information for these scales, as they are highly relevant to investment and infrastructure plan- ning. Such societal demands have motivated the present study, which describes several plausible climate scenarios in the Pampas and the potential impacts on the economic sustainability of agricultural systems.

\section{THE STUDY REGION}

We focus on 2 locations in the Pampas with different climatic and ecological characteristics: Pergamino (Buenos Aires province, $33^{\circ} 56^{\prime} \mathrm{S}, 60^{\circ} 33^{\prime} \mathrm{W}$ ) and Pilar (Córdoba province, $31^{\circ} 41^{\prime} \mathrm{S}, 63^{\circ} 53^{\prime} \mathrm{W}$ ), which represent near-optimal and relatively marginal agricultural conditions, respectively. Pergamino is in the most productive subregion of the Pampas, whereas Pilar is in the northern, semi-arid margin of the region (Paruelo \& Sala 1993, Dardanelli et al. 1997). Total rainfall and the annual precipitation cycle vary between locations. Median annual precipitation is $937 \mathrm{~mm}(738 \mathrm{~mm})$ in Pergamino (Pilar). In Pilar, the annual rainfall cycle has a marked winter minimum that, together with limited soil water storage, makes summer crops very dependent on spring precipitation. In contrast, the winter minimum in Pergamino is less marked. Precipitation at both sites has varied significantly over past decades. Median rainfall for October to March (spring to summer) in Pergamino increased by about $12 \%$ between 1931 to 1950 and 1975 to 1994; in Pilar rainfall showed a much higher increase of $33 \%$ between the same periods.

Pergamino has a long agricultural history, whereas agriculture has developed more recently in the area around Pilar. Currently, crop rotations at both sites include maize, soybean, and a wheat/soybean double crop (wheat followed by short-cycle soybean). Crop production technologies are similar at both locations. Contrasting agroecological conditions between sites allow us to explore differences in the vulnerability of the current agricultural systems to changing climate.

\section{APPROACH}

To assess how agricultural systems of the Pampas might respond to inter-decadal climate variability, we followed 5 main steps. First, we used historical climate records to define a set of plausible and relevant climate scenarios $25 \mathrm{yr}$ into the future. Second, we used a semi-parametric weather generator to downscale regional scenarios into multiple realizations of daily weather consistent with proposed decadal scenarios. Third, synthetic daily weather series, crop growth models, and realistic input and output prices were used to simulate agricultural outcomes (yields, economic returns) for a trend of interest (a plausible decrease in 
annual precipitation). Fourth, we explored how economic returns and risk metrics (probability of economic failure) might evolve for current cropping practices in the absence of adaptation, and given the prescribed precipitation trends. Finally, we investigated adaptive responses (e.g. changing allocation of farm land among crops) based on different types of decision-makers' reactions to climate trends. In the following sections we present a brief description of each step.

\subsection{Definition of plausible climate trajectories}

Substantial progress in global and regional modeling at medium to high spatial resolution provides the opportunity for using atmospheric-ocean global general circulation models (AOGCMs) to generate regional projections of temperature and precipitation (Tebaldi et al. 2006). There are concerns, however, that these models still are not capable of simulating regional climate for short time horizons to the levels of accuracy desirable to support effective and defensible policies or actions (Rosenzweig et al. 2004, Tebaldi et al. 2006). Boulanger et al. $(2006,2007)$ studied South American temperature and precipitation projections for the end of the 21st century; whereas they found consistency in projected temperature changes, there was considerable divergence among models in precipitation projections. Lack of consistency in AOGCM projections requires that we explore alternative approaches to the definition of climate scenarios for the 25 to $30 \mathrm{yr}$ timeframe on which we focus.

Our definition of climate scenarios followed Orlowsky et al. (2007). This approach was proposed as a reasonable starting point for regional impact studies. The central assumption is that weather states that have occurred in the past may occur again or very similarly in the near future. The dominance in short time horizons of natural variability over human-induced climate change underlies this assumption. Climate scenarios are constructed by resampling from historical series. The resampling is constrained by parameters from a regression line, which describe an observed trend in a certain climate variable.

Selection of plausible climate scenarios was based on past rainfall trends at each location. We computed total annual precipitation for Pergamino (1931 to 2004, $74 \mathrm{yr}$ ) and Pilar (1931 to 2005, $75 \mathrm{yr}$ ). Then, we fitted linear trends to precipitation totals over a series of overlapping 25 yr windows shifted by 1 yr. For example, the first window for Pilar encompassed 1931 to 1955, the second one, 1932 to 1956 , and so forth. The moving windows allow us to identify wet/dry epochs of arbitrary onset and duration and to avoid the assump- tion that climate varies in an idealized cyclic manner (Mauget 2003). To assess the robustness of trend estimates, we used different fitting methods: ordinary least-squares regression, a robust regression that minimized the impact of outliers, and non-parametric methods; we also tested 20 and 30 yr window spans.

All trend estimation methods yielded fairly similar results; for brevity we show the results for ordinary regression. Fig. 1 shows annual precipitation totals and the linear trends fitted for each $25 \mathrm{yr}$ window. Various patterns are apparent: (a) a precipitation decrease in Pergamino between the 1930s and the 1950s (although in Pilar this decrease is not as consistent), (b) a marked increase between the end of the 1950s and the early 1990s at both locations, and (c) a considerable decreasing trend in Pilar over the last 15 yr (this second decrease in Pergamino was not as consistent as in Pilar).

The slopes of fitted lines (Fig. 1) were used to project plausible trajectories of annual precipitation for the 25 yr from the end of existing data (i.e. 2005 to 2029 and 2006 to 2030 for Pergamino and Pilar, respectively;

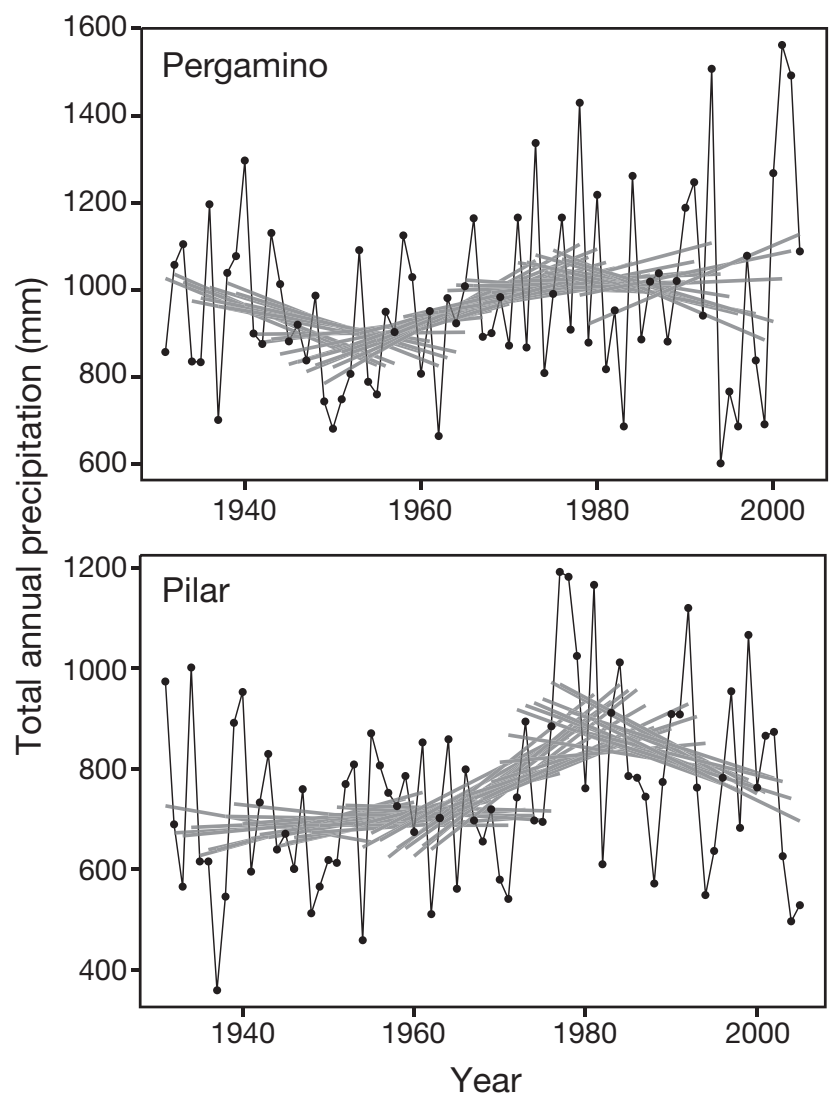

Fig. 1. Total annual precipitation for Pergamino (1931 to 2004) and Pilar (1931 to 2005). Light grey lines indicate the trends (fitted by ordinary least-squares regression) for overlapping 25 yr windows 
Fig. 2). Here we focus on 1 pattern only: a decrease in annual precipitation. Two reasons justify this choice. First, agriculture in the Argentine Pampas is largely rain fed, so production is highly sensitive to precipitation deficits. Second, stakeholders' concerns about a possible return to a drier epoch are growing, particularly for marginal regions where changes may be felt earlier. Nevertheless, we stress that by focusing on decreasing rainfall we do not imply that such trajectory is the likeliest. Indeed, the spread of fitted trends (Fig. 2) suggests a broad range of plausible scenarios.

To select a plausible decrease in future precipitation in Pilar, we averaged the estimated slopes for the 10 most recent $25 \mathrm{yr}$ windows: this average trend

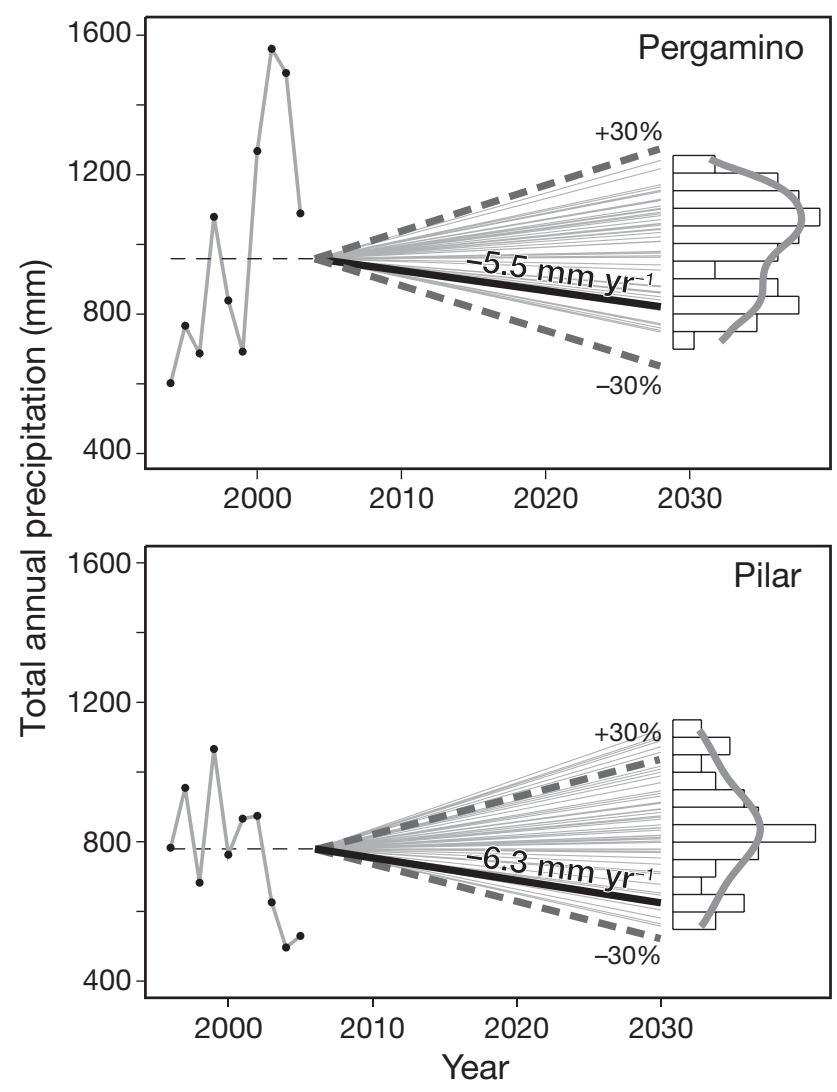

Fig. 2. Historical annual precipitation totals; grey lines: all linear trends (fitted by ordinary least-squares regression) for overlapping $25 \mathrm{yr}$ windows. Left sides of the figures show precipitation totals for 10 most recent years of available data (1995 to 2004 for Pergamino; 1996 to 2005 for Pilar). Median totals for these periods ( $980 \mathrm{~mm}$ for Pergamino, $775 \mathrm{~mm}$ for Pilar) were used as the point of departure for projections based on estimated trends. Thick black lines: 2 decreasing trends selected for further analysis. Histograms of projected precipitation totals $25 \mathrm{yr}$ into the future are shown on the right side of each panel. An empirical density was fit to the histogram to facilitate visualization of the distribution of trends. However, the histograms and densities should not be interpreted as a rigorous statement about the probability of each trend (indicated on Fig. 2, lower panel) was $-6.3 \mathrm{~mm} \mathrm{yr}^{-1}$. In Pergamino, in contrast, recent evolution of precipitation was less consistent: both positive and negative slopes were observed. For this reason, we estimated the average magnitude of consistently increasing trends for Pergamino between the 1950s and 1990s and then reversed its sign. That is, we assumed that precipitation could decrease at a rate comparable to previously observed increases. The resulting trend was $-5.5 \mathrm{~mm} \mathrm{yr}^{-1}$ (Fig. 2, upper panel). The starting point for projected rainfall trajectories was the median annual precipitation for the 10 most recent years on record: $980 \mathrm{~mm}$ (Pergamino) and $775 \mathrm{~mm}$ (Pilar).

\subsection{Temporal downscaling of selected rainfall trajectories}

The second step involved the temporal disaggregation of the selected climate trajectories into daily synthetic (simulated) series of the weather variables required by crop simulation models (maximum and minimum temperature, total daily precipitation, and solar radiation). We coupled a semi-parametric (or hybrid) method for the generation of daily weather sequences (Apipattanavis et al. 2007) and a biased resampling algorithm (Yates et al. 2003) that can replicate an observed low-frequency trend or simulate a hypothetical climate trajectory.

The semi-parametric approach to stochastic weather generation proposed by Apipattanavis et al. (2007) has 2 main components: (a) a Markov chain for generating the precipitation state (i.e. no rain, rain, or heavy rain) and (b) a k-nearest neighbor (k-NN) bootstrap re-sampler (Rajagopalan \& Lall 1999) for generating the remaining weather variables. The Markov chain correctly describes rainfall spell statistics, whereas the k-NN bootstrap captures the distributional and lag-dependence statistics of other variables.

Relevant climate scenarios can easily be incorporated into the weather generator framework. Resampling of the historical record is biased according to the trend one wishes to reproduce or simulate. Each historical year is weighted according to its 'closeness' (in terms of the conditioning variables) to the scenario for which weather sequences are to be generated (Yates et al. 2003, Clark et al. 2004). This step produced an ensemble of 100 equally likely sequences (each $25 \mathrm{yr}$ long) of simulated daily weather at each location. Each ensemble was consistent with the decadal trends considered. As an example, Fig. 3 displays boxplots of simulated annual precipitation for Pilar. 


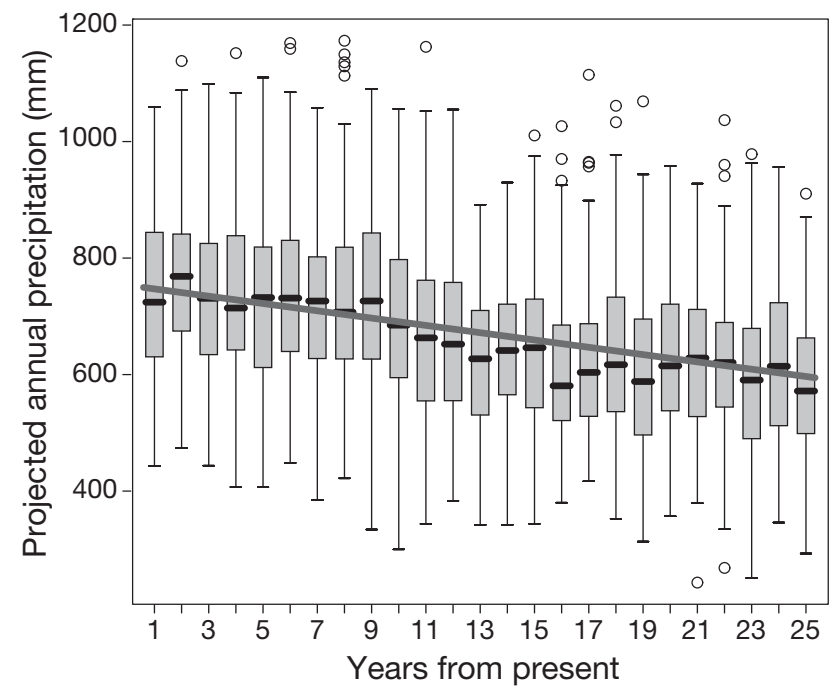

Fig. 3. Boxplot of projected annual precipitation totals in Pilar, showing the distribution of precipitation totals for the 100 realizations corresponding to each year in the sequence. Thick black horizontal line: median of the 100 realizations; box: central $50 \%$ of the distribution; whiskers and outlying circles: range of the data. Thick gray line superimposed on the boxplots: proposed decreasing trend $\left(-6.6 \mathrm{~mm} \mathrm{yr}^{-1}\right)$

\subsection{Simulation of crop yields and economic results}

Dynamic, process-level crop models simulate crop growth and development as a function of daily weather, soil type, and crop genetic characteristics. We used models in the Decision Support System for Agrotechnology Transfer (DSSAT) package (Jones et al. 1998). These models have been calibrated and validated in many production environments including the Pampas (Meira et al. 1999, Mercau et al. 2007). Model inputs such as 'genetic coefficients', describing physiological processes and developmental differences among genotypes, and soil parameters, including soil moisture and $\mathrm{N}$ content at the beginning of simulations, were provided by Asociación Argentina de Consorcios Regionales de Experimentación Agrícola (AACREA, www.aacrea.org.ar), a non-profit farmers' group that entered a partnership with us for the present study.

In consultation with AACREA experts, we defined representative current practices for each crop and location. To explore adaptation options, we also defined a suite of realistic alternative management conditions. In all, 12 (11) different crop/management combinations were defined for Pergamino (Pilar); details are shown in Table 1. For each management condition, crop yields were simulated by the DSSAT models using the 100 realizations of synthetic daily weather: 2400 simulated yields were obtained for each crop/ management condition, 1 for each cropping cycle ( 24 cycles can be simulated from 25 calendar years of synthetic weather) and realization.
A constant economic context (crop prices and input costs) was assumed for all analyses, providing an 'all else being equal' situation that helps isolate the effects of changing climate from impacts of quite different factors that sometimes may be closely interconnected (Parry 1985). For each crop/management condition, we computed economic profits per hectare, defined as the difference between gross income and costs. Gross income per hectare was the product of simulated yields and the median of crop prices from 2000 to 2005. Cost calculations were based on a representative 600 ha farm operated by its owner (i.e. no land rental costs were considered) and included both direct and indirect costs. Direct costs are associated with a particular crop/management condition and, in turn, can be divided into fixed costs (which do not depend on crop yields, e.g. seed, agrochemicals) and variable costs (that are a function of crop yields, e.g. transportation, commercialization). Indirect costs include farm-wide expenses such as real estate taxes and maintenance of farm structures; following local experts, indirect costs were assumed to be $\$ 70 \mathrm{ha}^{-1}$ for both locations.

\subsection{Impacts of changing climate on current agronomic practices}

Simulated economic profits were used to quantify impacts of rainfall decrease on current agricultural practices in the absence of adaptation. Fig. 4a shows a smoothed trajectory of simulated economic profits from the typical current management attributes (indicated in bold face in Table 1) for each crop and location.

The probability of negative economic returns (PNER) was used to quantify economic risks to production associated with climate trends. For the typical current management conditions for each crop, we computed PNER as the proportion of the 100 realizations for each cropping cycle in which simulated economic profits were negative. Fig. 4b shows smoothed variations in PNER along the simulated sequences for each crop and location.

\subsection{Adaptive responses to changing climate}

We explored the consequences of various types of adaptive responses based on different possible reactions to changing climate. For each type of adaptation, the response of a hypothetical farmer was characterized by the land allocation (i.e. the proportion of land allocated to each crop/management condition) that maximized a specific objective function or choice criterion. 
Table 1. Description of managements simulated for each crop in Pergamino and Pilar. Rows in bold: the management most representative of current practices for each crop. The table also shows the average trend in yields of each crop management along the simulated sequence of decreasing precipitations. The average yield trend was computed as the average of differences between smoothed yields in consecutive years of the sequence

\begin{tabular}{|c|c|c|c|c|c|c|}
\hline \multirow[t]{2}{*}{ Crop } & \multirow[t]{2}{*}{ ID } & \multirow[b]{2}{*}{ Genotype } & \multicolumn{2}{|c|}{ Crop management } & \multirow[b]{2}{*}{$\begin{array}{l}\text { Planting density } \\
\quad \text { (ind. } \mathrm{m}^{-2} \text { ) }\end{array}$} & \multirow[b]{2}{*}{$\begin{array}{l}\text { Avg. yield trend } \\
\quad\left(\mathrm{kg} \mathrm{ha}^{-1} \mathrm{yr}^{-1}\right)\end{array}$} \\
\hline & & & Planting date & $\begin{array}{l}\text { Fertilizer } \\
\left(\mathrm{kg} \mathrm{N} \mathrm{ha}^{-1}\right)\end{array}$ & & \\
\hline \multicolumn{7}{|l|}{$\underline{\text { Pergamino }}$} \\
\hline \multirow[t]{4}{*}{ Soybean } & Soy1 & DM-3700 & 15 Oct & 0 & 35.0 & 1.7 \\
\hline & Soy2 & DM-4800 & 15 Oct & $\mathbf{0}$ & 35.0 & 5.6 \\
\hline & Soy3 & DM-4800 & $15 \mathrm{Nov}$ & 0 & 35.0 & -1.2 \\
\hline & Soy 4 & DM-4800 & $15 \mathrm{Dec}$ & 0 & 35.0 & 2.2 \\
\hline \multirow[t]{4}{*}{ Maize } & Ma1 & DK-682 & 15 Sept & 140 & 7.5 & 7.9 \\
\hline & Ma2 & DK-682 & 15 Sept & 110 & 6.0 & 9.2 \\
\hline & Ma3 & DK-682 & 20 Oct & 140 & 7.5 & 19.4 \\
\hline & $\mathrm{Ma} 4$ & DK-682 & 20 Oct & 110 & 6.0 & 14.4 \\
\hline \multirow[t]{8}{*}{ Wheat/soybean } & WS1 & D. Enrique (wheat) & $1 \mathrm{Jul}^{\mathrm{a}}$ & 115 & 320.0 & -9.5 \\
\hline & & DM-4800 (soybean) & $\mathbf{0}$ & 35.0 & -5.7 & \\
\hline & WS2 & D. Enrique (wheat) & $1 \mathrm{Jul}^{\mathrm{a}}$ & 158 & 320.0 & -10.9 \\
\hline & & DM-4800 (soybean) & 0 & 35.0 & -5.7 & \\
\hline & WS3 & Guapo (wheat) & 1 Jun $^{a}$ & 115 & 280.0 & -17.0 \\
\hline & & DM-4800 (soybean) & 0 & 35.0 & 1.8 & \\
\hline & WS4 & Guapo (wheat) & 1 Jun $^{a}$ & 158 & 280.0 & -17.5 \\
\hline & & DM-4800 (soybean) & 0 & 35.0 & 1.8 & \\
\hline \multicolumn{7}{|l|}{$\underline{\text { Pilar }}$} \\
\hline \multirow[t]{3}{*}{ Soybean } & Soy1 & DM-3700 & 1 Nov & $\mathbf{0}$ & 35.0 & -23.4 \\
\hline & Soy2 & DM-4800 & $1 \mathrm{Nov}$ & 0 & 35.0 & -24.5 \\
\hline & Soy3 & DM-4800 & $1 \mathrm{Dec}$ & 0 & 35.0 & -19.8 \\
\hline \multirow[t]{4}{*}{ Maize } & Ma1 & AW190 & 20 Oct & 0 & 5.5 & -86.0 \\
\hline & Ma2 & AW190 & 20 Oct & 65 & 6.5 & -92.6 \\
\hline & Ma3 & AW190 & $10 \mathrm{Dec}$ & 0 & 5.5 & -76.4 \\
\hline & $\mathrm{Ma} 4$ & AW190 & $10 \mathrm{Dec}$ & 65 & 6.5 & -76.5 \\
\hline \multirow[t]{8}{*}{ Wheat/soybean } & WS1 & D. Enrique (wheat) & 15 Jun $^{a}$ & 0 & 320.0 & -19.6 \\
\hline & & DM-4800 (soybean) & 0 & 35.0 & -12.3 & \\
\hline & WS2 & D. Enrique (wheat) & 15 Jun $^{a}$ & 65 & 320.0 & -19.7 \\
\hline & & DM-4800 (soybean) & 0 & 35.0 & -12.2 & \\
\hline & WS3 & Guapo (wheat) & $30 \mathrm{Apr}^{\mathrm{a}}$ & 0 & 280.0 & -14.5 \\
\hline & & DM-4800 (soybean) & 0 & 35.0 & -16.5 & \\
\hline & WS4 & Guapo (wheat) & $30 \mathrm{Apr}^{\mathrm{a}}$ & 65 & 280.0 & -14.7 \\
\hline & & DM-4800 (soybean) & $\mathbf{0}$ & 35.0 & -16.4 & \\
\hline
\end{tabular}

The objective function that decision-makers seek to maximize has been the object of theoretical and empirical investigation for centuries (Machina 1987). The expected utility (EU) model has been widely used in agricultural economics. Despite its strengths, EU maximization as the sole objective of risky choice has recently encountered opposition (Gintis 2000, Jager et al. 2000, Shaw \& Woodward 2008). There is both experimental and real-world evidence that individuals often do not behave in a manner consistent with EU theory (Camerer 2000).

Prospect theory and its extension, cumulative prospect theory (CPT), have become the most prominent alternatives to EU theory (Tversky \& Kahneman 1992, Fennema \& Wakker 1997). For this reason, the $\mathrm{CPT}$ value is the choice criterion to be maximized in this work. The CPT value is defined in terms of relative gains or losses, that is, positive or negative deviations from a reference point. Value, therefore, is determined by changes in wealth, rather than absolute wealth as in utility theory (Kahneman 2003). The CPT value function is steeper for losses than for gains. This feature models loss aversion, i.e. the observation that the negative experience or disutility of a loss of a given magnitude is larger than the positive experience or utility of a gain of the same magnitude. The curvature of the function in each domain (gains and losses) reflects diminishing sensitivity in the evaluation of outcomes farther from the reference point. In another deviation from EU theory, CPT predicts that risk attitudes depend on how a problem is framed: risk-averse behavior will predominate if outcomes are perceived 

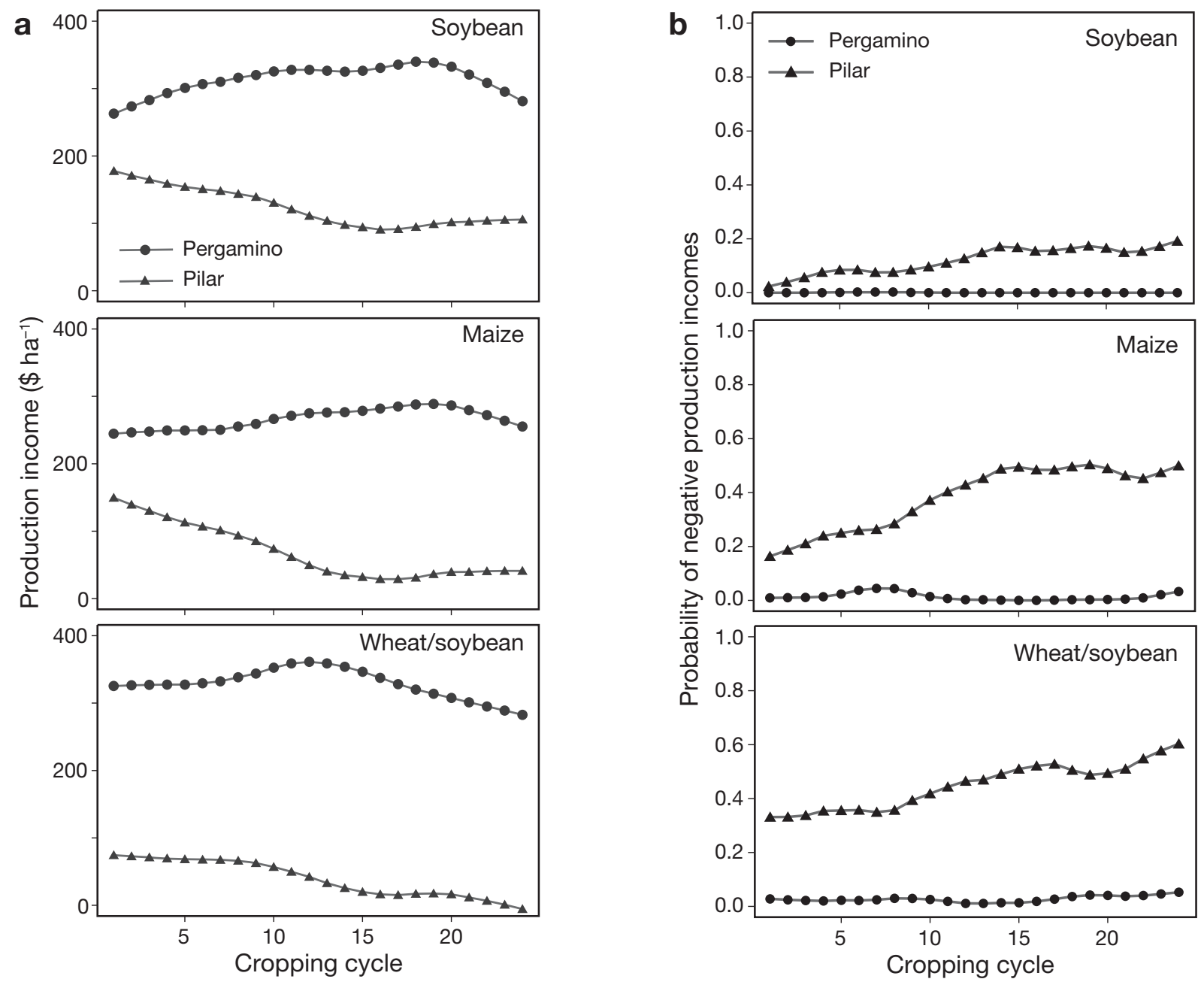

Fig. 4. Temporal evolution of (a) economic returns and (b) the probability of negative economic returns (a metric of production risk) for typical current management conditions for the 3 main cropping systems in both regions: from top to bottom, full-cycle soybean, maize, and a wheat/soybean double crop. To facilitate visualization of trends, smoothing was applied to the 2400 simulated profits (100 realizations for each cropping in the 24 -cycle sequence)

as gains, whereas risk-seeking behavior will prevail if outcomes are perceived as losses. Finally, CPT involves a weighting function that transforms objective probability distributions (Stott 2006).

We considered 3 kinds of adaptive responses to changes in climate. First, we simulated a 'naïve' farmer, who does not react to varying conditions. Throughout the simulated sequence, this farmer continues to follow the land allocation identified as optimal during the initial portion (Cropping Cycles 1 to 4 ) of the sequence. Second, we simulated a 'clairvoyant' farmer, who is perfectly aware of the range of expected climate conditions in each cropping cycle. Expected conditions in each cycle depend, on the one hand, on its position in the simulated sequence (cycles towards the end of the sequence are drier) and, on the other hand, on the natural variability contained in the 100 realizations of simulated weather. This case represents the complete opposite of the 'no management change' previously explored, as the farmer changes land allocation in each cropping cycle. Finally, a third group of simulations represents an intermediate situation in which a farmer changes his/her actions in each cropping cycle, but selects optimal land allocations based on the climate prevailing during the previous 4 cycles. For example, in Cycle 6 this farmer follows the optimal crop allocation derived using the 400 simulated profits for Cycles 2 to 5 .

Optimal land allocations for the different situations were identified using a genetic algorithm (GA), a technique that mimics biological evolution as a problemsolving strategy (Gilbert \& Troitzsch 1999). GAs work with a population of 'individuals,' each of which -in this case-represents a possible land allocation solution. An individual (or solution) was described by a 'chromosome' involving 20 integer-valued 'genes'; the 
value of each gene ranged from 1 to 11 (12), i.e. the number of crop/management conditions considered in Pilar (Pergamino). This representation is equivalent to partitioning a farm into 20 equal-sized cells (i.e. the solution has a resolution of $5 \%$ ), each allocated to a given crop/management condition. Each individual has a 'fitness': annual economic profits for a given allocation were calculated as an area-weighted combination of profits from all crop/management condtions involved; these profits were then converted into a CPT value representing the fitness of a solution.

The GA uses various heuristic operators to evolve an initial population of solutions so that each successive generation has, on average, a higher fitness than its predecessor. The process continues until the average fitness of a population has converged to an optimal value: the land allocation that maximizes the CPT value. Our implementation of the GA was verified against an exhaustive search procedure. We set the initial population at 150 individuals, which was a tradeoff between the diversity of solutions and computation time. We used cloning, simple mutation, adjacent mutation, and crossover operators (Seppelt \& Voinov 2002).

To perform the optimizations, parameters of the CPT value function had to be selected. This function is defined by: (1) a reference value $w$ that separates outcomes perceived as gains and losses, (2) a risk preference parameter $\alpha$, and (3) a loss aversion parameter $\lambda$ that quantifies the relative impact of losses over gains. The combination of all 3 parameters, together with the probability weighting function, determines observed levels of risk taking in CPT (Fennema \& Wakker 1997). We estimated $w$ as the income effortlessly achievable by renting out one's land instead of farming it; this income was assumed to be $\$ 170 \mathrm{ha}^{-1}\left(\$ 230 \mathrm{ha}^{-1}\right)$ for Pilar (Pergamino). We used nominal (or typical) $\alpha$ and $\lambda$ values proposed by Tversky \& Kahneman (1992): 0.88 and 2.25, respectively. Nominal values were also used for the curvature parameter $\gamma$ in the CPT's probability weighting function: 0.61 for gains and 0.69 for losses.

\section{RESULTS}

\subsection{Impacts of changing climate on current agronomic practices}

The decreasing precipitation trends explored had quite different impacts on the economic profits of current practices at each location (Fig. 4a). In Pergamino, profits for summer crops changed only slightly. In contrast, profits in Pilar showed a clear reduction: Pilar is a relatively marginal production area of the Pampas, and crop production is very sensitive to climate variability.

In Pilar, the most dramatic decrease was for the wheat/soybean double crop, which started with an average profit of about $\$ 80 \mathrm{ha}^{-1}$ and, by the end of the 24 yr sequence, reached average profits close to zero. For maize, the decrease in economic returns reached $75 \%$ of the initial value by the end of the $24 \mathrm{yr}$ sequence. Soybean was the least affected crop, as its average economic returns decreased to about $40 \%$ of the initial value.

In Pergamino, profits for all crops increased slightly during the initial years of the simulated sequences. Despite the decreasing trend, rainfall in Pergamino apparently remained sufficient to maintain or even slightly increase yields and profits of summer crops. The moderate profit increases may be related to higher radiation levels and decreases in minimum temperatures associated with a progressive decrease in the number of rainy days. However, near the end of the simulated sequences, water became a limiting resource and yields and profits of all crops decreased.

In Pilar, there was no interaction between the climate scenario and crop returns: full-cycle soybean always showed the highest economic profits, followed by maize, and, finally, by wheat/soybean. In contrast, in Pergamino, the ordering of crop profitability changed: wheat/soybean (the most water-demanding strategy) showed the highest economic returns during the early years of the sequences, but soybeans became most profitable after Cycles 15 and 16. Maize always showed the lowest profits. Of course, these results are based on the economic context typical of the last few years; the relative profitability of each crop may vary if the context changes.

For Pergamino, PNER (i.e. the risk of economic losses) for all crops was always close to zero and did not change noticeably with decreasing precipitation (Fig. 4b). Conversely, increases in PNER were much higher in Pilar: the PNER for maize increased almost 4 -fold throughout the $24 \mathrm{yr}$ sequence, from 0.15 to 0.55 . The risk increase was also very high for full-cycle soybean: the PNER rose from 0.05 to 0.20 . The chance of negative profits for the wheat/soybean double crop increased from 0.35 to 0.65 .

\subsection{Adaptation of crop management to decadal climate trends}

Fig. 5a shows the temporal evolution of farm-wide economic returns in Pilar for the 3 different types of adaptation we explored: a 'naïve' farmer, a 'clairvoyant' farmer, and the intermediate situation of basing adaptation on conditions during the previous 4 cropping cycles. Profits in Pilar are clearly different (signifi- 

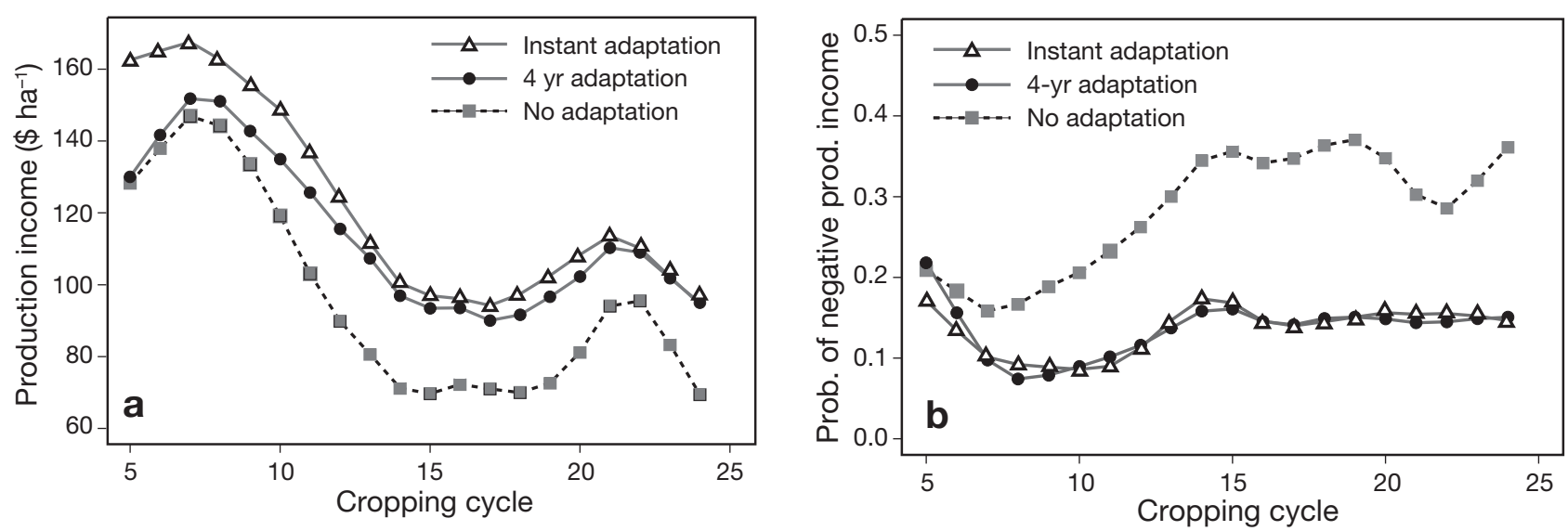

Fig. 5. Temporal evolution of (a) farm-wide economic returns and (b) the probability of negative farm-wide economic returns (a metric of production risk) in Pilar for 3 different types of farmer adaptation: (1) 'instant adaptation' corresponds to a 'clairvoyant' farmer, who is perfectly aware of the range of expected climate conditions and changes land allocation accordingly for each cropping cycle; (2) a farmer, who selects land allocation based on conditions during the preceding 4 cropping cycles; and (3) a naïve farmer ('no adaptation'), who does not react to changing climate conditions and continues to use the optimal land allocation identified for the initial portion of the sequence throughout the entire sequence. Results are displayed for Cycles 5 to 24 , as 2 of the adaptation mechanisms are delayed until Cycle 5 before land allocation is chosen

cantly lower) for farmers who do not adapt to decreasing precipitation. In contrast, differences between 'clairvoyant' and delayed adaptations are not as marked, although profits from instant adaptation are somewhat better, reflecting the unrealistic 'perfect expectations' of climate conditions. In short, even belated adaptation is better than no adaptation.

Similar conclusions can be derived from Fig. 5b, which shows the probability of farm-wide negative economic returns in Pilar for the various adaptation types. In the absence of adaptation, the probability of economic failure increases rapidly with decreasing precipitation, and towards the end of the sequence reaches about 0.35 (initially around 0.20 ). On the other hand, both types of adaptation appear to help stabilize the probability of negative returns, which remains fairly constant throughout the sequence.

Although our focus is not on the agronomic details of adaptation, in the following we discuss briefly the main land allocation patterns selected. In Pilar, at the beginning of the sequence (when precipitation still is sufficient), optimal allocation involves a large proportion of maize. This crop is profitable in Pilar because soils have a limited agricultural history and fertility is high (thus reducing the cost of fertilization). As rainfall decreases, land allocations switch to a combination of early planting soybean and wheat/soybean. In the second half of the sequence, optimal land allocation is dominated by late-planting soybean. This shift reflects the fact that Pilar has very dry winters and crop success is highly dependent on spring and summer rainfall. As precipitation decreases, a delay in planting date may be necessary to allow for water accumulation in the soil.
In Pergamino, there are no marked differences in profits or economic risks between the adaptation and no adaptation situations; therefore, no results are shown. Despite the lack of response of profits to decreasing rainfall, land allocations identified as optimal change throughout the sequences. For most of the 24 cropping cycles (up to Cycles 16 and 17) the optimal allocation involves about one-fourth of the land in wheat/soybean and three-fourths in full-cycle soybean. In the last portion of the sequence, however, optimal allocation changes to $100 \%$ soybean.

\section{DISCUSSION}

The present paper explored the potential impacts of plausible climate conditions $25 \mathrm{yr}$ into the future on agricultural systems in the Argentine Pampas. Interdecadal climate variability - together with changes in the economic and technological contexts - have contributed to recent, important changes in land use in the Pampas. Although there is still considerable uncertainty about the projected paths of future climate change, there is growing concern among stakeholders in the Pampas that agricultural production systems that evolved partly in response to increased rainfall may not be economically sustainable if climate reverts to a drier epoch.

Two locations in the Pampas, Pergamino and Pilar, representing, respectively, climatically optimal and marginal conditions, were selected for detailed analyses. Because of divergence in climate projections, particularly on short temporal horizons, we estimated plausible climate scenarios from fluctuations observed 
in the historical record (Orlowsky et al. 2007). Two decreasing linear trends consistent with previously experienced fluctuations, -5.5 and $-6.3 \mathrm{~mm} \mathrm{yr}^{-1}$ for Pergamino and Pilar, respectively, were chosen for detailed analysis. Nevertheless, we stress again that our focus on decreasing rainfall is a response to the concerns of stakeholders and does not imply that these particular trajectories are the most likely. Indeed, future studies should explore other equally plausible trends.

If precipitation decreases as projected and currently prevailing crop management conditions are not modified, stakeholders in Pilar might experience much lower profits and higher probabilities of negative economic results in the future. The riskiest crop in Pilar is wheat/soybean, as it demands greater amounts of water. The probability of economic losses for this crop doubles from once in $3 \mathrm{yr}$ to twice in $3 \mathrm{yr}$. Similarly, farmers in Pilar growing maize, who currently experience economic losses once every 6 or $7 \mathrm{yr}$, may, in the future, lose money in 5 of $10 \mathrm{yr}$.

There have been 2 equally unrealistic extremes in modeling farmers' adaptation to climate variability and change: a naïve farmer, who does not notice a changing context and makes decisions as always, and a 'clairvoyant' farmer, who tracks fluctuating climate precisely and follows the best adaptation strategies (Schneider et al. 2000). In reality, farmers are neither naïve nor clairvoyant (Risbey et al. 1999), but these extreme situations help us bracket possible responses. In between these 2 extremes, we also simulated a farmer who adapts to changing climate after a few cropping cycles. Profits in Pilar are clearly lower for farmers who do not adapt to decreasing precipitation. In contrast, differences between 'clairvoyant' and delayed adaptations are not as marked (although obviously profits from instant adaptation are slightly better). That is, any type of adaptation (including adaptation that is delayed) can help reduce the negative impacts of unfavorable climate scenarios such as the rainfall decrease we considered.

Although land allocations identified as optimal changed throughout the simulated sequences for Pergamino, profits and economic risks did not change significantly, even in the absence of adaptation. Clearly, if precipitation changes are greater than those simulated here, even this region may show negative impacts. In contrast, both sets of simulated results (with and without adaptation) for Pilar highlight the much greater sensitivity of climatically marginal regions: the decrease in profits and increase in risks was much more marked than in Pergamino. A trend towards drier conditions may endanger future viability of continuous agriculture in marginal regions of the Pampas, where farmers already operate near the limits of profitability and have a slender buffer against hardship.
Forthcoming advances in agricultural technology may affect not only the sector's productivity, but also its vulnerability to climate changes (McKenney et al. 1992). Future studies should consider adaptation options that involve, not only changes in proportions of currently available genotypes or management conditions (as we have done), but also technological innovations. For instance, it is relevant to ask whether crop breeding can keep pace with projected yield decreases associated with the rainfall trends considered. For Pilar, simulated yield decreases for different maize management conditions range from 76 to $93 \mathrm{~kg} \mathrm{ha}^{-1} \mathrm{yr}^{-1}$ (Table 1). Crop breeding, in contrast, has produced recent average yield increases of 100 to $250 \mathrm{~kg} \mathrm{ha}^{-1} \mathrm{yr}^{-1}$ (Luque et al. 2006). Projected decreases in full-cycle soybean yields in Pilar are 20 to $25 \mathrm{~kg} \mathrm{ha}^{-1} \mathrm{yr}^{-1}$ (Table 1). Unlike maize, projected drops in soybean yields compare unfavorably with recent breeding increases of 12 to $16 \mathrm{~kg} \mathrm{ha}^{-1} \mathrm{yr}^{-1}$ (Santos et al. 2006). In any case, it would be critical to assess whether realistic rates of yield enhancement would be enough to compensate for the negative impacts of unfavorable climate trends.

To plan for adaptation, it is important to anticipate the technological changes that may shape agriculture over the next decades. One of the most anticipated developments in agricultural biotechnology is the introduction of genes to enhance drought tolerance in plants (Babu et al. 2003, Masle et al. 2005). Maize is the main alternative to soybean in the Pampas, and its yields are very sensitive to drought-related stresses. The availability of drought-tolerant maize may allow cropping in a marginal area that becomes even drier. Furthermore, rotations including drought-tolerant maize would become more attractive in a drier climate and partially alleviate concerns about soybean mono-cropping.

In the next few decades, complex interactions between decadal climate variability, technological innovations, and other drivers will force agricultural stakeholders and policy-makers to face unavoidable tradeoffs between productivity, stability, and sustainability in agroecosystems of the Pampas (Viglizzo \& Roberto 1998). The growing tension between multiple and conflicting objectives, coupled with incomplete and uncertain information about expected climate trajectories and other valid societal concerns offer opportunities for salient scientific knowledge to inform decisionmaking and policy.

Acknowledgements. This research was supported by 2 U.S. National Science Foundation Coupled Natural and Human Systems grants (0410348 and 0709681). Additional support was provided by the U.S. National Oceanic and Atmospheric Administration's Climate Program Office through its Sectoral Applications Research Program (SARP, Grant GC04-159), and 
a grant from the Inter-American Institute for Global Change Research (IAI, CRN-2031), which is supported by the U.S. National Science Foundation (Grant GEO-0452325). F.B. was supported by fellowships from Argentina's Consejo Nacional de Investigaciones Científicas y Técnicas (CONICET). The authors are grateful to the management, technical advisors, and farmer members of the Asociación Argentina de Consorcios Regionales de Experimentación Agrícola (AACREA) for their commitment to this research. Climate data were provided by the Argentine Meteorological Service. G.P. thanks the Intergovernmental Panel on Climate Change's Task Group on Data and Scenario Support for Impact and Climate Analysis (IPCC-TGICA) for its invitation to the June 2007 regional meeting in Nadi, Fiji.

\section{LITERATURE CITED}

Apipattanavis S, Podestá GP, Rajagopalan B, Katz RW (2007) A semiparametric multivariate and multisite weather generator. Water Resour Res 43:W11401

Babu RC, Nguyen BD, Chamarerk V, Shanmugasundaram P and others (2003) Genetic analysis of drought resistance in rice by molecular markers: association between secondary traits and field performance. Crop Sci 43:1457-1469

Berbery H, Doyle M, Barros V (2006) Tendencias regionales de la precipitación. In: Barros V, Clarke R, Silva Dias P (eds) El cambio climático en la Cuenca del Plata. CONICET, Buenos Aires

Boulanger JP, Leloup J, Penalba O, Rusticucci M, Lafon F, Vargas W (2005) Observed precipitation in the ParanáPlata hydrological basin: long-term trends, extreme conditions and ENSO teleconnections. Clim Dyn 24:393-413

Boulanger JP, Martínez F, Segura EC (2006) Projection of future climate change conditions using IPCC simulations, neural networks and Bayesian statistics. I. Temperature mean state and seasonal cycle in South America. Clim Dyn 27:233-259

Boulanger JP, Martínez F, Segura EC (2007) Projection of future climate change conditions using IPCC simulations, neural networks and Bayesian statistics. II. Precipitation mean state and seasonal cycle in South America. Clim Dyn 28:255-271

Camerer C (2000) Prospect theory in the wild. In: Kahneman D, Tversky A (eds) Choice, values, and frames. Cambridge University Press, New York

Clark MP, Gangopadhyay S, Brandon D, Werner K, Hay L, Rajagopalan B, Yates D (2004) A resampling procedure for generating conditioned daily weather sequences. Water Resour Res 40:W04304

Dardanelli JL, Bachmeier OA, Sereno R, Gil R (1997) Rooting depth and soil water extraction patterns of different crops in a silty loam Haplustoll. Field Crops Res 54:29-38

Fennema H, Wakker P (1997) Original and cumulative prospect theory: a discussion of empirical differences. J Behav Decis Making 10:53-64

Gilbert N, Troitzsch KG (1999) Simulation for the social scientist. Open University Press, Philadelphia

Gintis H (2000) Beyond Homo economicus: evidence from experimental economics. Ecol Econ 35:311-322

Giorgi F (2002) Variability and trends of sub-continental scale surface climate in the twentieth century. I. Observations. Clim Dyn 18:675-691

Hall AJ, Rebella CM, Ghersa CM, Culot JP (1992) Field-crop systems of the Pampas In: Pearson CJ (ed) Ecosystems of the world. Field crop ecosystems. Elsevier, Amsterdam, p 413-449
Haylock MR, Peterson MC, Alves LM, Ambrizzi T and others (2006) Trends in total and extreme South American rainfall in 1960-2000 and links with sea surface temperature. J Clim 19:1490-1512

Jager W, Janssen MA, De Vries HJM, De Greef J, Vlek CAJ (2000) Behaviour in commons dilemmas: Homo economicus and Homo psychologicus in an ecological-economic model. Ecol Econ 35:357-379

Jones J, Tsuji G, Hoogenboom G, Hunt L and others (1998) Decision support system for agrotechnology transfer. In: Tsuji G, Hoogenboom G, Thornton PK (eds) Understanding options for agricultural production. Kluwer, Dordrecht, p 157-177

> Kahneman D (2003) Perspective on judgment and choice: mapping bounded rationality. Am Psychol 58:697-720

$>$ Luque SF, Cirilo AG, Otegui ME (2006) Genetic gains in grain yield and related physiological attributes in Argentine maize hybrids. Field Crops Res 95:383-397

Machina M (1987) Choice under uncertainty: problems solved and unsolved. J Econ Perspect 1:121-154

> Magrín GO, Travasso MI, Rodríguez GR (2005) Changes in climate and crop production during the 20th century in Argentina. Clim Change 72:229-249

Masle J, Gilmore SR, Farquhar GD (2005) The ERECTA gene regulates plant transpiration efficiency in Arabidopsis. Nature 436:866-870

> Mauget SA (2003) Intra- to multidecadal climate variability over the continental United States: 1932-99. J Clim 16: 2215-2231

McKenney MS, Easterling WE, Rosenberg NJ (1992) Simulation of crop productivity and responses to climate change in the year 2030: the role of future technologies, adjustments and adaptations. Agric For Meteorol 59:103-127

Meinke H, Nelson R, Kokic P, Stone R, Selvaraju R, Baethgen W (2006) Actionable knowledge: from analysis to synthesis. Clim Res 33:101-110

Meira S, Baigorri E, Guevara E, Maturano M (1999) Calibration of soybean cultivars for two environments in Argentina. Global Soy Forum 1999, Chicago, Aug 6-7, 1999

Mercau JL, Dardanelli JL, Collino JM, Andriani A, Irigoyen A, Satorre EH (2007) Predicting on-farm soybean yields in the Pampas using CROPGRO-soybean. Field Crops Res 100:200-209

Minetti JL, Vargas W (1997) Trends and jumps in the annual precipitation in South America, south of the $15^{\circ} \mathrm{S}$. Atmósfera 11:205-221

Minetti JL, Vargas W, Poblete AG, Acuña LR, Casagrande G (2003) Non-linear trends and low frequency oscillations in annual precipitation over Argentina and Chile, 1931-1999. Atmósfera 16:119-135

Orlowsky B, Gerstengarbe FW, Werner PC (2008) A resampling scheme for regional climate simulations and its performance compared to a dynamical RCM. Theor Appl Clim 92:209-223

Parry ML (1985) The impact of climatic variations on agricultural margins. In: Kates RW, Ausuble $\mathrm{JH}_{\text {, Berberian M }}$ (eds) Climate impact assessment. John Wiley, New York, p 351-367

Parry ML, Carter TR (1989) The impact of climate change on agriculture. In: Topping JC (ed) Coping with climate change: proceedings of the 2nd North American conference on preparing for climate change. Climate Institute, Washington, DC, p 180-184

> Paruelo JM, Sala OE (1993) Effect of global change on maize production in the Argentinean Pampas. Clim Res 3:161-167

Paruelo JM, Guerschman JP, Verón SR (2005) Expansión agrícola y cambios en el uso del suelo. Ciencia Hoy 15:14-23 
Rajagopalan B, Lall U (1999) A k-nearest-neighbor simulator for daily precipitation and other weather variables. Water Resour Res 35:3089-3101

Risbey J, Kandlikar M, Dowlatabadi H, Graetz D (1999) Scale, context, and decision making in agricultural adaptation to climate variability and change. Mitig Adapt Strategies Glob Change 4:137-165

Rosenzweig C, Strzepek KM, Major DC, Iglesias A, Yates DN, McCluskey A, Hillel D (2004) Water resources for agriculture in a changing climate: international case studies. Global Environ Change A 14:345-360

Rusticucci M, Penalba O (2000) Interdecadal changes in the precipitation seasonal cycle over southern South America and their relationships with surface temperature. Clim Res 16:1-15

Santos D, Fresoli D, Beret P, Benavidez R, Vicentini R, de la Vega AJ (2006) Ganancia genética en soja en Argentina entre 1980 y 2000. Available at: www.inta.gov.ar/ PARANA/info/documentos/produccion_vegetal/soja/ evaluacion_manejo/20220_060524_gan.htm

Satorre EH (2005) Cambios tecnológicos en la agricultura actual. Ciencia Hoy 15:24-31

Schneider SH, Easterling WE, Mearns LO (2000) Adaptation, sensitivity to natural variability, agent assumptions and dynamic climate changes. Clim Change 45:203-221

Schnepf RD, Dohlman E, Bolling C (2001) Agriculture in Brazil and Argentina: developments and prospects for major field crops. Economic Research Service Agriculture and Trade Report, U.S. Department of Agriculture, Wash-

Submitted: July 28, 2008; Accepted: April 30, 2009 ington, DC, p 85

Seppelt R, Voinov A (2002) Optimization methodology for land use patterns using spatially explicit landscape models. Ecol Model 151:125-142

Shaw WD, Woodward RT (2008) Why environmental and resource economists should care about non-expected utility models. Resour Energy Econ 30:66-89

Stott HP (2006) Cumulative prospect theory's functional menagerie. J Risk Uncertain 32:101-130

Tebaldi C, Hayhoe K, Arblaster JM, Meehl GA (2006) Going to the extremes: an intercomparison of model-simulated historical and future changes in extreme events. Clim Change 79:185-211

Tversky A, Kahneman D (1992) Advances in prospect theory, cumulative representation of uncertainty. J Risk Uncertain 5:297-323

Viglizzo EF, Roberto ZE (1998) On trade-offs in low-input agroecosystems. Agric Syst 56:253-264

Viglizzo EF, Roberto ZE, Filippin MC, Pordomingo AJ (1995) Climate variability and agroecological change in the central Pampas of Argentina. Agric Ecosyst Environ 55: $7-16$

Viglizzo EF, Roberto ZE, Lértora F, Lopez Gay E, Bernardos J (1997) Climate and land use change in field crop ecosystems of Argentina. Agric Ecosyst Environ 66:61-70

Yates D, Gangopadhyay S, Rajagopalan B, Strzepek K (2003) A technique for generating regional climate scenarios using a nearest-neighbor algorithm. Water Resour Res 39(7):1199, doi: 10.1029/2002WR001769

Proofs received from author(s): August 31, 2009 